\title{
FAT INTAKE, SERUM CHOLESTEROL CONCENTRATION, AND ATHEROSCLEROSIS IN THE SOUTH AFRICAN BANTU. PART II. ATHEROSCLEROSIS AND CORONARY ARTERY DISEASE
}

\author{
By J. HIGGINSON AND W. J. PEPLER
}

\author{
(From the Department of Pathology, Baragwanath Hospital; and the South African Institute \\ for Medical Research, Johannesburg, South Africa)
}

(Submitted for publication June 16, 1953; accepted June 9, 1954)

No vital statistics are available for the Bantu of South Africa, and knowledge of their disease pattern is dependent on clinical impressions and on examination of hospital material, which is, of necessity, selected. The numerous fallacies involved in the interpretation of hospital statistics, especially for heart disease, have recently been reviewed by Mainland (1). Unfortunately, however, such sources at present provide the only adequate information available for the Bantu.

There is, however, widespread clinical belief that the more severe complications of atherosclerosis, i.e., coronary and cerebral thrombosis, angina pectoris and intermittent claudication, are rare among Africans. This impression may be due partly to the small number of Africans living to an advanced age. For example, in 1951 only 17 per cent of the patients (excluding children) attending Baragwanath Non-European Hospital were found to be over 45 years of age, in contrast to the figure of 47 per cent for Europeans at the Johannesburg General Hospital. A sample of the population from the native township of Alexandra near Johannesburg in 1953, has shown that rather less than 8 per cent are over 50 years of age (2). That the lower longevity of Africans is not the only reason, however, is suggested by the work of other authors. In Rhodesia, Gelfand $(3,4)$ has reported that, in his experience, coronary artery disease is very infrequent. Severe atheroma and coronary artery disease have been recorded as uncommon in Uganda (5). In a comprehensive review of post-mortem material among the Bantu in Johannesburg, Becker (6) concluded that coronary thrombosis with infarction was rare.

\section{MATERIAL}

The subjects in the present study were in-patients dying in Baragwanath Hospital, the largest general hospital serving mainly the Bantu in Johannesburg and surround- ing townships of the Witwatersrand. In the local study of Alexandra Native township (2) from which many of these patients are drawn, it was found that practically all the Bantu population were prepared to attend a Western hospital when seriously ill. There is no evidence of bias in the attendance of cardiac patients in the general hospitals in the Johannesburg area.

Post-mortem examinations are obtained in approximately one-third of the general patients dying at this hospital. The majority of patients on whom a necropsy is not performed are surgical cases, infants and young children. Apart from these cases, the major reason for not doing a post-mortem, is failure to obtain permission from a relative. We have no evidence that this permission is biased for any particular disease or section of the Bantu community. Cases where there is factual evidence of an unnatural cause of death such as motor accidents and stabbings, are sent to the Government Medico-Legal Laboratories. In 1953, approximately one-third of the deaths registered in the Johannesburg magisterial district were from this hospital, but the exact figure is not known as some patients may go from hospital to their birthplace in the country, if seriously ill, and death certificates are not corrected to district of domicile.

In relation to atherosclerosis, there may be some bias due to the following cause. All clinicians at this hospital agree that if coronary artery disease is suspected in a Bantu out-patient, every attempt is made to secure his admission due to the suspected rarity of the condition. This factor accordingly tends to increase rather than decrease the proportion of patients with severe coronary atherosclerosis seen at post-mortem.

\section{METHODS}

Coronary artery and aortic atherosclerosis. A series of 523 unselected necropsies, performed under the supervision of one pathologist at Baragwanath Hospital, were available for study, with adequate records on the condition of the aorta and coronary vessels. The primary cause of death for these patients is given in Table I. It should also be pointed out, however, that many showed, in addition, histological lesions in the liver of the type described in a previous paper from this hospital (7), although not showing clinical evidence of hepatic disease. For comparative purposes an attempt was made to follow the classification of atherosclerosis described by Wanscher, Clemmesen, and Nielsen (8) in Denmark. 
Grade I. Cases with no obvious naked-eye lesions, and those with only slight fatty streaking and minimal atherosclerosis in the aorta and/or coronary arteries.

Grade II. A more marked degree of atherosclerosis with the plaques tending to be confluent, but without obvious ulceration, or significant diminution of the lumen of the coronary arteries.

Grade III. Severe atherosclerosis of aorta, including ulceration and calcification, but in which atherosclerosis of the coronary arteries does not significantly diminish the lumen.

Grade IV. Cases with marked atherosclerosis of the coronary arteries.

These cases are frequently but not invariably associated with well-marked aortic disease.

As in the Danish series, cases of aneurysm and syphilitic aortitis have been excluded. Further, cases of malignant disease have been omitted as in the Danish series, since the latter authors have demonstrated a markedly reduced incidence of severe atherosclerosis in cancer patients in contrast to patients dying without cancer.

The above classification essentially depends on the general appearance on naked-eye examination of the arteries, especially the aorta. The main disadvantages are the high degree of subjectivity, and the failure to allow for differences in the degree of atherosclerosis between the coronary arteries and the aorta. In our experience the degree of atherosclerosis in each is not necessarily comparable. Accordingly, while the classification in Grades I. to III corresponds reasonably closely to that described by the Danish authors, being chiefly dependent on the condition of the aorta, this is not true for Grade IV, in which we have included all cases with severe coronary disease, even if the degree of aortic change was slight.

In our series the coronary arteries were examined by opening them along their major branches, so that direct comparison with the excellent studies of White, Edwards, Dry, and Ackerman $(9,10)$ in Minnesota was not possible. It can be stated, however, by correlation of naked-eye and microscopic appearances, that if the coronary arteries showed plaques approximately of Grade II atherosclero-

TABLE I

Cause of death as established at necropsy

\begin{tabular}{|c|c|c|c|}
\hline Primary cause of death & Men & Women & Total \\
\hline $\begin{array}{l}\text { Cardio-vascular disease (including } \\
\text { tuberculous pericarditis) } \\
\text { Tuberculosis } \\
\text { Central nervous system disease } \\
\text { Respiratory disease } \\
\text { Miscellaneous bacterial and para- } \\
\text { sitic diseases } \\
\text { Genito-urinary disease } \\
\text { Primary liver disease } \\
\text { Diabetes mellitus } \\
\text { Gastro-intestinal disease } \\
\text { Miscellaneous }\end{array}$ & $\begin{array}{r}18 \\
26 \\
12 \\
3 \\
14 \\
15\end{array}$ & $\begin{array}{r}21 \\
38 \\
6 \\
4 \\
4 \\
20\end{array}$ & $\begin{array}{r}39 \\
64 \\
18 \\
7 \\
18 \\
35\end{array}$ \\
\hline Total & 300 & 223 & 523 \\
\hline
\end{tabular}

TABLE II

Incidence of atherosclerosis at necropsy

\begin{tabular}{|c|c|c|c|c|c|c|c|c|}
\hline \multirow{3}{*}{$\begin{array}{c}\text { Age } \\
\text { group } \\
\text { (years) }\end{array}$} & \multicolumn{7}{|c|}{ Grade } & \multirow[b]{3}{*}{ Total } \\
\hline & \multicolumn{2}{|r|}{ I } & \multicolumn{2}{|c|}{ II } & III & \multicolumn{2}{|c|}{ IV } & \\
\hline & No. & $\%$ & No. & $\%$ & No. \% & No. & $\%$ & \\
\hline \multicolumn{9}{|c|}{ a. In 300 adult men } \\
\hline $\begin{array}{l}20-29 \\
30-39 \\
40-49 \\
50-59 \\
60-69 \\
70+\end{array}$ & $\begin{array}{r}46 \\
57 \\
50 \\
14 \\
15 \\
3\end{array}$ & $\begin{array}{l}85 \\
77 \\
65 \\
32.5 \\
37 \\
27\end{array}$ & $\begin{array}{r}6 \\
16 \\
24 \\
26 \\
19 \\
7\end{array}$ & $\begin{array}{l}11 \\
22 \\
31 \\
60.5 \\
46 \\
64\end{array}$ & $\begin{array}{ll}1 & 2 \\
1 & 1 \\
2 & 3 \\
2 & 5 \\
3 & 7 \\
0 & \end{array}$ & $\begin{array}{l}1 \\
0 \\
1 \\
1 \\
4 \\
1\end{array}$ & $\begin{array}{r}2 \\
1 \\
2 \\
10 \\
9\end{array}$ & $\begin{array}{l}54 \\
74 \\
77 \\
43 \\
41 \\
11\end{array}$ \\
\hline
\end{tabular}

b. In 223 adult women

\begin{tabular}{|c|c|c|c|c|c|c|c|c|}
\hline $\begin{array}{l}20-29 \\
30-39 \\
40-49 \\
50-59 \\
60-69 \\
70+\end{array}$ & $\begin{array}{r}59 \\
41 \\
25 \\
8 \\
6\end{array}$ & $\begin{array}{l}98 \\
79 \\
61 \\
30 \\
24 \\
11\end{array}$ & $\begin{array}{l}1 \\
11 \\
16 \\
15 \\
14 \\
11\end{array}$ & $\begin{array}{r}2 \\
21 \\
39 \\
55 \\
56 \\
61\end{array}$ & \multicolumn{2}{|c|}{$\begin{array}{l}- \\
- \\
\begin{array}{ll}3 & 11 \\
5 & 20 \\
4 & 22\end{array}\end{array}$} & E & $\begin{array}{c}- \\
- \\
-4 \\
6\end{array}$ \\
\hline
\end{tabular}

sis or less according to the classification illustrated by these authors (9), they were not graded as Grade IV above in our classification. Only those cases, in which more than one of the atheromatous plaques present appeared of greater severity, were placed in Grade IV in this series. Although this grading was done by nakedeye examination, in nearly all Grade III and Grade IV cases a section from the coronary arteries was available.

The Danish authors described the coronary arteries in Grade IV as being "transformed to stiff and narrow chalky pipes without elasticity." It is our opinion that not a single case graded as IV by us, could be justifiably so described. Accordingly, we have attempted to be as critical

TABLE III

Comparison: Grade III and IV atherosclerosis in Bantu and Danish series

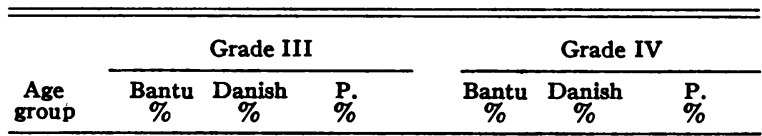

\begin{tabular}{|c|c|c|c|c|c|c|}
\hline & & & $a$. & & & \\
\hline $40-49$ & 3 & 32 & $<1$ & 1 & 8 & Not \\
\hline 50-59 & 5 & 50 & $<1$ & 2 & 10 & $\begin{array}{l}\text { Not } \\
\text { significant }\end{array}$ \\
\hline $\begin{array}{l}60-69 \\
70+\end{array}$ & $\begin{array}{l}7 \\
0\end{array}$ & $\begin{array}{l}45 \\
48\end{array}$ & $\begin{array}{l}<1 \\
<1\end{array}$ & $\begin{array}{r}10 \\
9\end{array}$ & $\begin{array}{l}21 \\
37\end{array}$ & $\begin{array}{l}<1 \\
<1\end{array}$ \\
\hline
\end{tabular}

\section{b. Women}

\begin{tabular}{|c|c|c|c|c|c|c|}
\hline $40-49$ & 0 & 20 & Not & 0 & 0 & Not \\
\hline $50-59$ & 11 & 32 & $\begin{array}{l}\text { significant } \\
\text { Not } \\
\text { significant }\end{array}$ & 4 & 6 & $\begin{array}{l}\text { significant } \\
\text { Not }\end{array}$ \\
\hline $\begin{array}{l}60-69 \\
70+\end{array}$ & $\begin{array}{l}20 \\
22\end{array}$ & $\begin{array}{l}46 \\
42\end{array}$ & $\begin{array}{l}<1 \\
<1\end{array}$ & $\begin{array}{l}0 \\
6\end{array}$ & $\begin{array}{l}21 \\
45.5\end{array}$ & $\begin{array}{l}<1 \\
<1\end{array}$ \\
\hline
\end{tabular}


TABLE IV

Distribution of cases dying from coronary diseases in relation to total necropsies and cardiac deaths

\begin{tabular}{|c|c|c|c|c|}
\hline$\underset{\text { group }}{\text { Age }}$ & $\begin{array}{c}\text { Total } \\
\text { post- } \\
\text { mortems }\end{array}$ & $\begin{array}{c}\text { Cardiac } \\
\text { deaths }\end{array}$ & $\begin{array}{l}\text { Coronary } \\
\text { disease }\end{array}$ & $\begin{array}{c}\text { Per cent } \\
\text { coronary } \\
\text { deaths } \\
\text { out of } \\
\text { total } \\
\%\end{array}$ \\
\hline \multicolumn{5}{|c|}{ a. Men } \\
\hline \multirow[t]{2}{*}{$\begin{array}{c}20-29 \\
30-39 \\
40-49 \\
50-59 \\
60-69 \\
70+ \\
\text { Unknown }\end{array}$} & $\begin{array}{r}124 \\
193 \\
212 \\
121 \\
103 \\
42 \\
12\end{array}$ & $\begin{array}{r}27 \\
50 \\
62 \\
34 \\
21 \\
18 \\
2\end{array}$ & $\begin{array}{l}0 \\
0 \\
1 \\
1 \\
0 \\
2 \\
0\end{array}$ & $\begin{array}{l}\overline{-} \\
\overline{0.5} \\
0.8 \\
\overline{5} \\
-\end{array}$ \\
\hline & 807 & 214 & 4 & 0.5 \\
\hline \multicolumn{5}{|c|}{ b. Women } \\
\hline $\begin{array}{c}20-29 \\
30-39 \\
40-49 \\
50-59 \\
60-69 \\
70+ \\
\text { Unknown }\end{array}$ & $\begin{array}{r}129 \\
122 \\
89 \\
73 \\
52 \\
45 \\
11\end{array}$ & $\begin{array}{r}17 \\
34 \\
27 \\
16 \\
19 \\
14 \\
1\end{array}$ & $\begin{array}{l}0 \\
0 \\
0 \\
1 \\
0 \\
3 \\
0\end{array}$ & $\begin{array}{l}\bar{z} \\
\frac{\overline{1.5}}{4.5} \\
-\end{array}$ \\
\hline & 521 & 128 & 4 & 0.6 \\
\hline
\end{tabular}

as possible of our data, and it is probable that several cases graded as III or IV in this series would have been graded less by the Danish workers.

Table II gives the number of cases in each grade. In Table III the number of cases graded as III and IV are compared with the corresponding Danish groups.

The degree of nutrition is probably lower than in the Minnesota series (10), in that only 1.7 per cent of the males and 10.7 per cent of the females were described in our protocols as stout or obese, whereas 39.4 per cent of males and 33.3 per cent of females were considered poorly nourished. In the Minnesota series 38.8 per cent of the females were described as over-weight and 22.3 per cent under weight.

Coronary artery disease. In a larger series of 1,328 consecutive necropsies carried out by various members of the staff at the same hospital over a period of five and one-half years and which includes the previous series, there were seven cases of coronary thrombosis or myocardial infarction, and one case in which the diagnosis of ischemic heart disease was considered tenable.

In Table IV is shown the distribution of these cases in relation to the total number of post-mortem and cardiac deaths.

\section{COMMENTS}

In common with other African reports $(5,6)$, the number of cases in the older age groups is small in both our series.
As already mentioned a classification as used in Tables II and III is unsatisfactory due to the high degree of subjectivity. But, as the criteria for severe atheroma (Grade III and IV) are clearly stated by the Danish authors ( 8 ), we believe that, in the absence of a more satisfactory classification, a comparison between these two groups is justified with the following qualification. Of this series of 523 post-mortems, in no aorta was a degree of atherosclerosis found comparable to that described as Grade IV aortic disease by the Danish authors, and our cases were placed in this category on account of the condition of the coronary arteries. To exclude the possibility that this observation was not due to differences of interpretation, we compared samples of our aortas in the older age groups with a group of unselected aortas from South African European subjects in the same age groups, kindly put at our disposal by Dr. B. J. P. Becker of this Institute. These European subjects were from the Johannesburg General Hospital. The crude death rate from arteriosclerotic and degenerative heart disease for the white population of South Africa was 153.6 per 100,000 of the population in 1949, in contrast to 268.1 in the United States (11). The severe degrees of atherosclerosis observed in the majority of these European aortas have not been seen by us in Bantu subjects.

The value of statistical analysis for such data, nevertheless, is doubtful and has only been calculated at the 1 per cent level using the method described by Hald (12). However, the difference between the Danish and Bantu figures (Table III) is sufficiently marked to indicate that severe atherosclerosis is relatively infrequent among the Bantu. These data which depend mainly on the aorta, are supported by our findings in the coronary arteries, although the relationship between atherosclerosis of the coronary arteries and aorta is not absolute. Gordon, Bland, and White (13), in a series of 3,400 post-mortems from Massachussetts General Hospital, found that 12.8 per cent of the cases in the 41 to 60 age group and 13.3 per cent in the 61 to 80 age group, showed occlusion of the coronary arteries. The corresponding figures in our series were 1.6 per cent in the 40 to 59 age group, and 3 per cent in the over 60 age group.

In the Minnesota series (9) previously mentioned, over 60 per cent of hearts from male cases over 50 years of age showed sclerosis with 50 per 
cent closure of the lumen in some part of the coronary system. In our study we considered that only 7 per cent of male hearts in this age group showed atherosclerotic plaques of this severity. This cannot be stated with absolute certainty, however, due to the different method of examination, but we do not consider it probable that we have missed coronary narrowing of this degree.

That these observations may be valid is supported by the low frequency of deaths from coronary artery disease observed at this hospital. From Minneapolis, in a series of 22,149 post-mortems from non-diabetic patients, Clawson and Bell (14) found that coronary artery disease was the major cause of death in 10.7 per cent of male and in 5.3 per cent of female deaths between 50 and 69 years of age. The corresponding figures at Baragwanath Hospital are 0.45 per cent and 0.8 per cent respectively (Table IV).

In Minnesota, Clawson (15) ascribed 24 per cent of cases of death from non-congenital heart disease, including all age groups, primarily to coronary disease. This proportion, of course, is influenced by the age composition of the hospital population. In our total series (Table IV), however, only 5.7 per cent of cardiac deaths in patients over 50 years of age were primarily due to coronary disease.

Our results are in conformity with those of Becker (6) who found only one Bantu death due to coronary thrombosis among a series of 352 predominantly Bantu post-mortems over the age of 50 years. Although not conclusive, these observations suggest that severe atherosclerosis of the aorta and coronary arteries are less frequent in the hospitalized Bantu in the Witwatersrand of South Africa than among the American and Danish hospital populations.

\section{DISCUSSION}

Assuming our conclusion to be valid, namely that the incidence of severe atherosclerosis in the Bantu is lower than in Europe and America, there are two possible explanations. In these people, atherosclerosis has developed more slowly, or secondly, the atherosclerotic lesions have regressed before death.

We are not aware of any pathological confirmation of regression taking place in severe atherosclerosis in man. However, regression may be in- voked as an explanation of the lower incidence of severe atherosclerosis in cancer patients than in non-cancer patients observed by Wanscher, Clemmesen, and Nielsen (8), also for the lower incidence reported in under weight patients from the United States $(10,16)$.

In regard to the genesis of atherosclerosis, it is now generally accepted that many factors are implicated, and recent work has reemphasized the importance of local vascular lesions such as intimal thrombosis and fibrosis, also medial degeneration (17-20). No detailed study of local vascular lesions has as yet been reported in the Bantu, but one of us (W. J. P.) in a series of 150 consecutive necropsies has observed some degree of medial degeneration in the aorta in every case over 20 years of age (21). Further, fibro-elastic thickening and elastic degeneration of the intima as described by Moon and Rinehart (20) have been observed in all adult patients in which the coronary arteries were examined microscopically. However, the quantitative relationship of these factors to the development of atherosclerosis in the Bantu has not been elucidated.

The influence of race must also be considered in view of the observations of Blache and Handler (22) who, in discussing the generally accepted lower incidence of coronary artery disease in the American Negro in contrast to the white American, have also shown that local degenerative changes in the coronary vessels develop more slowly in the negro. It is difficult, however, to explain the differences in the number of deaths from atherosclerosis in closely related races or even changes in mortality in the same race at different periods as described by Morrison (23), if local lesions are to be postulated as the sole cause of atherosclerosis. We would accordingly agree with Gutman who considers lipid metabolism of basic importance in the development of atherosclerosis (24), and prefer at present to regard the low frequency of severe atherosclerosis in the Bantu as possibly due to metabolic factors, rather than entirely due to racial and local vascular changes.

As stated in Part I of this study (25), fat intake and serum cholesterol concentration and possibly habituation to a refined low residue diet are regarded as factors influencing the development of severe atherosclerosis. In Europe and America it has not been possible to produce direct evidence 
in man on the exact rôle of fat intake and serum cholesterol levels in the pathogenesis and severity of atherosclerosis. In primitive communities the acquisition of statistics from a migrating and poorly controlled population is much more difficult than in Western countries, and, for the reasons stated, it has not been possible in this investigation to utilize comparable hospital groups. We believe, however, that our studies have demonstrated that Bantu hospital patients drawn from a population habituated to a low fat high residue diet have a lower incidence of severe atherosclerosis than Danish and American hospital populations; secondly, a series of out-patients at the same hospital also have lower serum cholesterol concentrations than groups taken from the general population in Denmark and the United States. Further work is being continued at this Institute on the comparative development of atherosclerosis in the Bantu and European races in South Africa, with special regard to the influence of local vascular lesions, and general differences in diet and metabolism.

\section{SUMMARY}

An examination of post-mortem material at Baragwanath Non-European Hospital shows that severe atherosclerosis and coronary artery disease are less common among Bantu patients attending this hospital, than in American and Danish hospital populations.

Some of the possible aetiological factors causing this lower incidence of atherosclerosis have been briefly mentioned. Attention is drawn to the low level of serum cholesterol among out-patients and in-patients attending this hospital reported in the first part of this study (25). These observations are in accord with the belief that populations with a low serum cholesterol tend to have a lower incidence of severe atherosclerosis.

\section{ACKNOWLEDGMENT}

Our thanks are due to Dr. B. J. P. Becker and Dr. J. F. Murray for advice and criticism in the preparation of this paper, and to Mr. W. Lutz of the University of the Witwatersrand for statistical assistance.

\section{REFERENCES}

1. Mainland, D., The risk of fallacious conclusions from autopsy data on the incidence of diseases with applications to heart disease. Am. Heart J., 1953, 45, 644.
2. Higginson, J., Oettle, A. G., and Navid, H., Unpublished.

3. Gelfand, M., The sick African, A Clinical Study, Cape Town, The Printing Stewart \& Co., Ltd., 1944, p. 11, 207.

4. Gelfand, M., Recent advances in tropical medicineNo. 3, Cardiac and vascular disorders in the African. West African M. J., 1952, 1 (New Series) 91.

5. Davies, J. N. P., Pathology of Central African Natives. Mulago Hospital postmortem studies. IX. East African M. J., 1948, 25, 454.

6. Becker, B. J. P., Cardio-vascular disease in the bantu and coloured races of South Africa. IV. Atheromatosis. South African J. M. Sc., 1946, 11, 97.

7. Higginson, J., Gerritsen, Th., and Walker, A. R. P., Siderosis in the Bantu of South Africa. Am. J. Path., 1953, 29, 779.

8. Wanscher, O., Clemmesen, J., and Nielsen, A., Negative correlation between atherosclerosis and carcinoma. Brit. J. Cancer, 1951, 5, 172.

9. White, N. K., Edwards, J. E., and Dry, T. J., The relationship of the degree of coronary atherosclerosis with age, in men. Circulation, 1950, 1, 645.

10. Ackerman, R. F., Dry, T. J., and Edwards, J. E., Relationship of various factors to the degree of coronary atherosclerosis in woman. Circulation, 1950, $1,1345$.

11. Epidem. vital Statist. Rep. (World Health Organization), 1952, 5, 378.

12. Hald, A., Statistical theory with engineering applications. New York, John Wiley \& Sons, Inc., 1952, p. 705 .

13. Gordon, W. H., Bland, E. F., and White, P. D., Coronary artery disease analyzed post-mortem; with special reference to the influence of economic status and sex. Am. Heart. J., 1939, 17, 10.

14. Clawson, B. J., and Bell, E. T., Incidence of fatal coronary disease in non-diabetic and in diabetic persons. Arch. Path., 1949, 48, 105.

15. Clawson, B. J., Coronary sclerosis. An analysis of nine hundred twenty eight cases. Am. Heart J., 1939, 17, 387.

16. Wilens, S. L., Bearing of general nutritional state on atherosclerosis. Arch. Int. Med., 1947, 79, 129.

17. Duguid, J. B., Thrombosis as a factor in the pathogenesis of aortic atherosclerosis. J. Path. \& Bact., 1948, 60, 57.

18. Wilens, S. L., The nature of diffuse intimal thickening of arteries Amer. J. Path., 1951, 27, 825.

19. Taylor, H. E., The role of mucopolysaccharides in the pathogenesis of intimal fibrosis and atherosclerosis of the human aorta. Am. J. Path., 1953, 29, 871.

20. Moon, H. D., and Rinehart, J. F., Histogenesis of coronary arteriosclerosis. Circulation, 1952, 6, 481.

21. Pepler, W. J., Unpublished work. 
22. Blache, J. O., and Handler, F. P., Coronary artery disease. A comparison of the rates and patterns of development of coronary arteriosclerosis in the negro and white races with its relation to clinical coronary artery disease. Arch. Path., 1950, 50, 189.

23. Morrison, L. M., Diet and atherosclerosis. Ann. Int. Med., 1952, 37, 1172.
24. Gutman, A. B., Present status of atherosclerosis as a derangement of lipid metabolism. Am. J. Med., $1953,14,1$.

25. Walker, A. R. P., and Arvidsson, U. B., Fat intake, serum cholesterol concentration, and atherosclerosis in the South African Bantu. Part I. Low fat intake and the age trend of serum cholesterol concentration in the South African Bantu. J. Clin. Invest., 1954, 33, 1358. 